\title{
APLICAÇÃO DO DESIGN DE PRODUTO EM PRÁTICAS DE RECUPERAÇÃO FLORESTAL ATRAVÉS DE SISTEMA DE SEMEADURA AÉREA
}

Daniel de Souza Gamarano, Mestrando. Universidade do Estado de Minas Gerais dgdanielgamarano@gmail.com

Carlos Alberto Silva de Miranda. Dr. Universidade do Estado de Minas Gerais carlosasmiranda@gmail.com

Artur Caron Mottin, M.Sc.

Universidade do Estado de Minas Gerais mottindesign@gmail.com

Caroline Salvan Pagnan, M.Sc.

Universidade do Estado de Minas Gerais carolinespagnan@gmail.com

Resumo: O desmatamento por queimadas em regiões de difícil acesso é um problema grave, tanto para combate quanto para recuperação destas áreas degradadas. Estimativas apontam que exista apenas $7 \%$ da Mata Atlântica nativa no território brasileiro. $\mathrm{O}$ artigo tem por objetivo mapear sistemas conceituais de semeadura e apresentar como o design pode ser uma ferramenta capaz de compreender, analisar e propor soluções que visem à melhoria do procedimento de reflorestamento por vias aéreas. Para alcançar este objetivo foram levantadas propostas de projetos disponíveis em plataformas on-line e que posteriormente com suas informações foram analisadas e verificadas a complexidade das propostas. Nota-se que grande parte das propostas disponíveis é complexa e pouco usual, do ponto de vista econômico. Algumas utilizam de sistemas complexos e excesso de material aplicado, tornando a proposta, mesmo no âmbito conceitual, imprópria para aplicação. Ao final do artigo é apresentado o projeto realizado, que visa reduzir a complexidade dos sistemas, baixo custo produtivo e otimização no uso de materiais e processos.

Palavras-chave: Reflorestamento; projetos conceituais; design e materiais.

Abstract: Fire deforestation in difficult access areas is a serious problem, both for fighting and for recovery of these degraded areas. Estimates suggest that there is only $7 \%$ of native Atlantic forest in Brazil. The article aims to map conceptual seeding systems enabling air reforestation. Project proposals available on online platforms were raised and subsequently with 
their information were analyzed and verified the complexity of the proposals. We notice that many of the available proposals are complex and unusual from the economics point of view. Some complex systems applied and excess material, making the proposals, even at the conceptual level, unfit for use. At the end of the article presents the realized project, which aims to reduce the complexity of systems, low cost production and optimize the use of materials and processes.

Keywords: Reforestation; conceptual projetcs; design and materials.

\section{INTRODUÇÃO}

Segundo REIS (2010), vivemos em uma época de transição, no qual há cada vez mais a preocupação dos indivíduos com a repercussão de seus comportamentos diários, uma vez que as escolhas que fazemos, como atuamos e nos posicionamos frente aos atuais problemas socioambientais, influenciam diretamente uma enorme cadeia de acontecimentos. Cada vez mais há a preocupação com a triple bottom line (pessoa, planeta e lucro, ou seja, a integração dos níveis social, ambiental e econômico), sendo que as escolhas pessoais se tornam mais exigentes frente à realidade atual produtiva, extremamente capitalista e predatória de recursos naturais. Dessa forma, muitas empresas começam a repensar seus produtos e serviços como forma de reduzir os impactos ambientais.

Associados a isso, conforme explica KAZAZIAN (2005), o crescimento populacional exponencial contribui para o desencadeamento de diversos problemas ambientais, relativos à sobrevivência humana, como moradia, alimentação e abastecimento de água e sistema de esgoto, bem como a possibilidade de consumo básico de vestimentas, transporte, fatores culminantes para a ampliação de problemas ambientais tais como poluição, queimadas e desmatamentos.

Em relação ao desmatamento, conforme a FAO (State of the World Forest), em 2001, as florestas cobriam cerca de 3,87 bilhões de hectares no mundo, representando um terço das terras emersas. O desmatamento ocorre mundialmente pela ação humana e fez com que $70 \%$ das florestas primárias (florestas não plantadas nas quais o homem não interferiu) do planeta tenham desaparecido, contribuindo para o aumento de cerca de $20 \%$ das emissões anuais de $\mathrm{CO}_{2}$ na atmosfera (KAZAZIAN 2005).

Segundo o IBAMA (1990), a prática de desmatamento pode ser entendida como:

(...) a operação que objetiva a supressão total da vegetação nativa de determinada área para o uso alternativo do solo. Considera-se nativa toda vegetação original, remanescente ou regenerada, caracterizada pelas florestas, capoeiras, cerradões, cerrados, campos, campos limpos, vegetações rasteiras, dentre outros (...)

A realidade atual do desmatamento no Brasil entrou em discussão, principalmente no ano de 2012, quando foi aprovado o novo Código Florestal. Dentre as características que ainda são questionadas, relacionam-se aos mecanismos de incentivo econômico à conservação, à restauração florestais não eficientes, as ferramentas que determinarão as áreas a serem preservadas e recuperadas em cada 
estado e bioma não foram definidas, além da falta de implantação Cadastro Ambiental Rural (CAR), necessário para a regularização ambiental de propriedades. Através desse cadastramento, o governo teria um panorama geral das propriedades rurais do país, para, posteriormente, identificar as que possuem alguma pendência ambiental (BOURSCHEIT, 2013).

Neste contexto, a prática de reflorestamento tem sido amplamente divulgada como forma de minimizar os impactos ambientais em áreas degradadas. $\mathrm{O}$ processo consiste em recuperar a floresta através do plantio de espécies nativas, preferencialmente de caráter regional, de forma a ampliar a manutenção da vida local. Vários são as preocupações acerca sobre o tema, indo desde a escolha dos espécimes reflorestados, a disponibilidade de recursos hídricos, a qualidade do solo, bem como a possibilidade de realizar o plantio. Nesse aspecto, várias são as formas utilizadas atualmente, indo desde o plantio de sementes e mudas, em terrenos planos realizados de forma manual ou mecânica, até a dispersão de sementes por vias aéreas, como helicópteros e aviões, como forma de alcançar áreas de difícil acesso que não seriam alcançadas de outra maneira.

O presente artigo tem como objetivo desenvolver um levantamento dos sistemas de semeadura que possibilite a dispersão de sementes por via aérea de forma a minimizar os impactos ambientais, e entender como o design pode ajudar no desenvolvimento deste segmento.

\section{DESENVOLVIMENTO}

O reflorestamento aéreo se diferencia do terrestre em diversos aspectos. Dentre eles, se destacam a facilidade de manejo, organização e dispersão das sementes, processo menos oneroso que o tradicional, além da redução de tempo de plantio, a não danificação da cultura, pois não 'amassa ' as sementes; e por ser um processo seguro (SILVEIRA, 2004).

Todavia, a efetividade do processo é reduzida (germinação das sementes), se comparada ao plantio da muda; não há uma difusão exata das sementes no meio a ser replantado; não há proteção das sementes no ambiente enquanto esta estiver se desenvolvendo. Associados a isso, os problemas da dispersão de longas altitudes, como o impacto da semente no solo, também são aspectos pertinentes de serem avaliados.

\subsection{Reflorestamento}

A reposição florestal é definida como o conjunto de ações que visam estabelecer a continuidade do abastecimento de matéria prima florestal dos diversos segmentos consumidores, através da obrigatoriedade de repor o volume explorado ou consumido, mediante o plantio de espécies florestais adequadas às suas finalidades (IBAMA, 1990).

Até o início dos anos 80 , as primeiras metodologias de reflorestamento adotadas no Brasil resultaram em plantios aleatórios e na simplificação dos reais problemas enfrentados, graças ao uso de espécimes nativos e exóticos (não pertencentes àquela região), a desconsideração da sucessão ecológica e o favorecimento do plantio de apenas espécies produtores de madeira, as quais possuem um crescimento lento. O foco principal era a composição de uma fisionomia 
vegetal, independente de suas características, caracterizando assim uma restauração sem critérios ecológicos (BELLOTTO; GANDOLFI; RODRIGUES, 2009).

A partir da década de 1980, com o desenvolvimento da ecologia da restauração, os projetos começaram a considerar o desuso de espécies exóticas, que em muitos casos se tornavam pragas em ecossistemas, pela falta de predadores naturais e condições de reprodução e crescimento favorável. Assim, as práticas de reflorestamento passaram a priorizar plantas naturais locais, dando a estas regiões características originais (BRANCALION et al., 2009).

Muitos avanços ainda são necessários no processo de restauração florestal para se garantir que as florestas replantadas e remanescentes exerçam o efetivo papel de mantenedoras da biodiversidade. Os avanços atuais estão em torno de pesquisas relativas à melhoria da variabilidade genética dos espécimes plantados, em criações controladas de sementes e mudas, além do controle de pragas e agentes biológicos com a mínima utilização de produtos químicos. (RODRIGUES; BRANCALION; ISERNHAGEN, 2009).

\subsection{Sistemas de semeadura utilizados no reflorestamento}

Existem diferentes processos que podem ser utilizados para o plantio e implantação de mudas em uma região, e para o processo de reflorestamento devem ser realizados prezando-se a diversidade de espécies e sua substituição gradual no terreno. Dentre as técnicas, foram analisadas as mais comumente empregadas, como o plantio manual de mudas e sementes, à dispersão por vias aéreas.

\subsection{1 .Plantio manual de Mudas}

Método utilizado para o plantio de mudas oriundas de viveiros ou abrigos, que contenham sacos plásticos. É realizado o plantio manual em casos onde não é possível a mecanização, e é uma atividade de baixo rendimento e que ocasiona grande desconforto físico ao trabalhador. Em muitos casos, faz-se necessário a abertura de covas para a inserção da planta, devendo posteriormente ser compactada a região (RODRIGUES; BRANCALION; ISERNHAGEN, 2009).

\subsubsection{Plantio com plantadora}

Neste caso, o plantio é realizado com o auxílio de equipamentos denominados plantadores, que permitem que o trabalhador, ao manusear as mudas, as insira já perfurando o solo, de modo a facilitar o processo e promover uma melhor postura corporal no trabalho (RODRIGUES; BRANCALION; ISERNHAGEN, 2009).

\subsubsection{Semeadura direta}

Técnica que vem sendo estudada para a realização tanto de reflorestamento quanto de enriquecimento de áreas pobres em quesito de variedade de espécies. Neste caso, há relatos de processos mecanizados, com utilização de tratores, arados, e semeadoras, bem como manual. Na semeadura direta, são utilizadas sementes, devendo respeitar as necessidades de cada espécie (de quantidade de solo sobre a 
mesma após o plantio, por exemplo). Ressalta-se que processos como adubação, irrigação e controle de espécies exóticas são variáveis em cada caso (RODRIGUES; BRANCALION; ISERNHAGEN, 2009).

\subsubsection{Semeadura aérea}

A semeadura aérea é realizada através da dispersão de sementes por meio de equipamentos de pás fixas ou móveis, ou seja, aviões ou helicópteros. Para isso, as sementes podem, ou não, estar protegidas de alguma forma. Cápsulas ou suspensão aquosa, como na hidrossemeadura, são exemplos de como proteger a semente. Este processo é o mesmo utilizado para a reabilitação de encostas de morros em estradas.

A aviação para fins agrícolas é praticada em todo o mundo, tendo como principais representantes os Estados Unidos, a Austrália e a Nova Zelândia. É utilizada desde a aplicação de agroquímicos até a recuperação de áreas degradadas (JÚNIOR, 2009). Ademais, os adventos das monoculturas em grande escala, para atender o consumo de populações urbanas cada vez maiores, sempre almejaram tecnologias que pudessem contribuir para uma maior efetivação do processo (SILVEIRA, 2004). O primeiro voo realizado com intuito agrícola no Brasil ocorreu em 1947 em Pelotas, no Rio Grande do Sul, para o combate de uma infestação de gafanhotos em áreas cultivadas (JÚNIOR, 2011).

Com relação às práticas de reflorestamento, destaca-se o realizado na Serra do Mar, em 1980, como apresenta a Figura 1. A cidade paulista de Cubatão sofria um forte processo de degradação ambiental realizado, sobretudo, pelos complexos petroquímicos, siderúrgicos e de fertilizantes instalados próximos às encostas, os quais elevaram a poluição em níveis alarmantes, destruindo parte da Mata Atlântica presente na região. Desencadeou-se assim uma grande quantidade de deslizamentos que colocou em risco as áreas urbanas e industriais. Para atenuar os estragos, a Companhia de Tecnologia de Saneamento Ambiental de São Paulo (CETESB) lançou, em 1984, um programa de controle da poluição que, em cinco anos, reduziu em $78 \%$ as emissões das 300 indústrias poluidoras identificadas na área. Depois desta etapa, foi elaborado um programa de reflorestamento aéreo para recompor, com espécies nativas, a vegetação afetada das encostas da serra. Em 1985, pesquisadores começaram a delimitar as estratégias de ação e em quatro anos, realizaram o modelo inédito do país, até então, de reflorestamento aéreo (IPT, 1989).

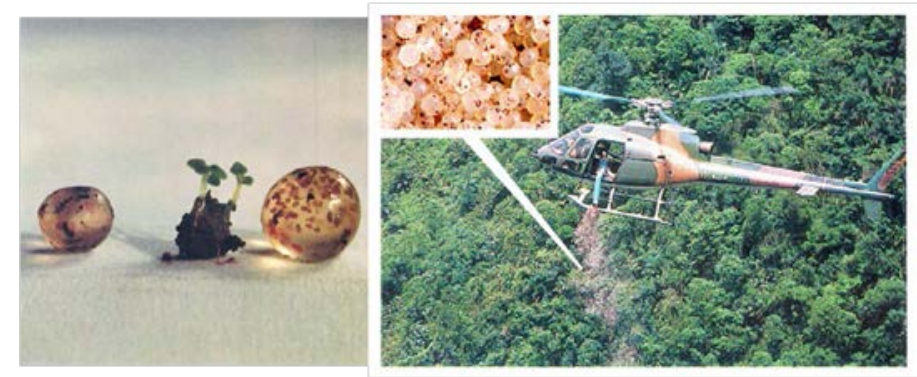

Figura 1 - Pelotas de gelatina contendo sementes em germinação e semeadura realizada por helicópteros sob a Serra do Mar.

Fonte: IPT

A solução encontrada para o lançamento das sementes foi através da peletização em gel hidrofílico composto de alginato de sódio $\left(\mathrm{NaC}_{6} \mathrm{H}_{7} \mathrm{O}_{6}\right)$ e cloreto de cálcio $\left(\mathrm{CaCl}_{2}\right)$. 
A peletização, além de proteger a semente e dar os subsídios iniciais de umidade que a semente necessitava, teve uma importância significativa ao lançamento por helicóptero, uma vez que elevou o peso da semente, facilitando que, ao longo de sua queda, chegasse ao solo. Ademais, o polímero utilizado conferiu transparência para que a planta germinasse, sendo biodegradável e não tóxico (IPT, 1989).

O sistema de reflorestamento por avião já tem sido utilizado em culturas como nabo, aveia, gramíneas e arroz. Todavia, ainda é um processo oneroso e ainda pouco difundido, o que valida à necessidade de projetos e estudos na área.

\subsection{Projetos de design vinculados ao reflorestamento aéreo}

Selecionaram-se projetos de design de produto conceituais relacionados ao reflorestamento aéreo, como o Seed Bomb e o Nucleário. Nota-se que ambas as propostas utilizam-se de polímeros biodegradáveis, reduzindo o impacto no meio ambiente. São estruturas complexas pensadas para reflorestar, demandando quantidades significativas de material e estrutura. Estes projetos foram selecionados a fim de exemplificar como o tema é amplamente estudado, porém carece de projetos que unam o processo projetual de designers com a abordagem das atuais pesquisas científicas sobre o tema.

O projeto proposto partiu da abordagem da biomimética em projetos de produto, e como alguns conceitos foram pertinentes para o entendimento dos métodos de dispersão natural das sementes, que culminaram na solução final.

\subsubsection{Seed Bomb (2009)}

O projeto conceitual proposto pelos designers Hwang Jin Wook, Kim Ji Myoung, Jeon Yoo Ho e Han Kuk Li, da Konkuk University (Coréia do Sul) é uma forma de alcançar áreas de difícil acesso, 'bombardeando' a região com sementes. Quando a Seed Bomb é lançada de um avião (Figura 2), há o processo de separação das cápsulas com sementes, dispersando-se ao longo do perímetro. Alojadas em polímero biodegradável, possuem um solo artificial que proporciona a umidade necessária para o crescimento, até serem suficientemente capazes de se nutrir.

Nesse caso temos duas situações: À medida que as plantas se desenvolvem, o polímero degrada-se, reflorestando a área (REIS, 2010).

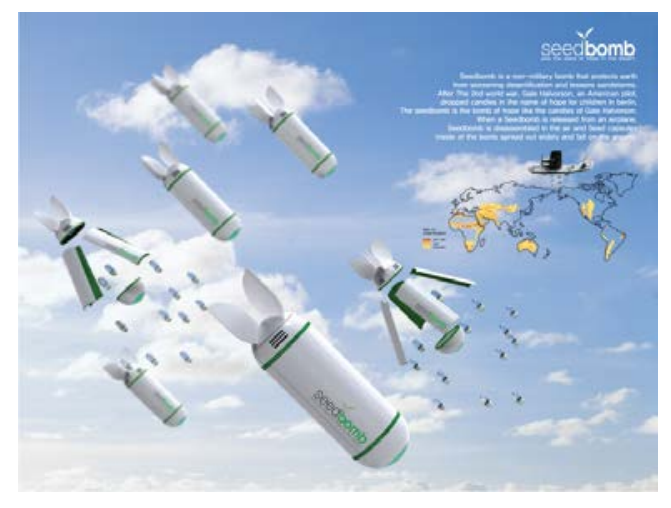

Figura 2 - Projeto SeedBomb.

Fonte: http://www.coroflot.com/Jinwook/seedbomb 


\subsubsection{Nucleário (2009)}

Projeto de graduação desenvolvido pelo designer Bruno Pagnocelli (Figura 3). 0 projeto foi concebido para o reflorestamento aéreo, e por meio de um disco de papelão, há a estabilidade dos núcleos de polímero biodegradável. O sistema foi projetado para permitir a entrada de umidade necessária para a semente, sem que elementos externos possam chegar a ela (como formigas e outros possíveis predadores). Com o desenvolvimento da planta, a cápsula desintegraria (PAGNOCELLI, 2013).

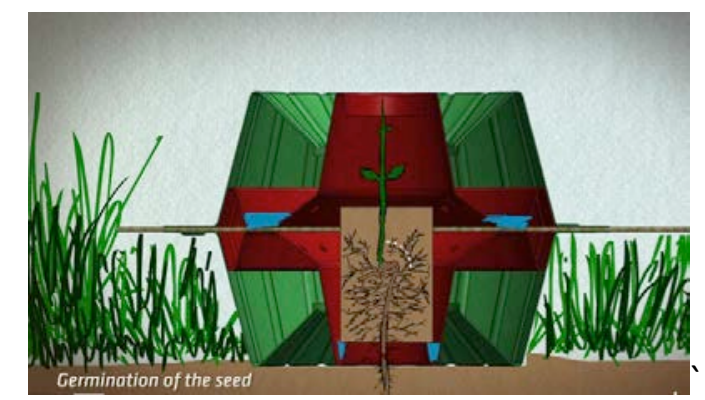

Figura 3 - Projeto Nucleário.

Disponível em http://vimeo.com/40417949/

\subsection{Biomimética}

A Biomimética define a área da ciência que estuda as estruturas biológicas e suas funções, procurando compreender a natureza, para retirar dela algum ensinamento - ou conceito básico. A palavra biomimética é de origem grega, proveniente das palavras bíos e mímesis, significando 'a imitação da vida'. Além desse termo, tem-se a Biônica e a Biomecânica, compreendidas como as ciências que estudam determinados processos biológicos dos seres vivos (mecanismos mecânicos e eletrônicos) a fim de aplicar processos análogos na área técnica e na indústria (GUIMARÃES, 2011).

Para GUIMARÃES (2011), a natureza pode ser comparada a um grande designer, o qual projeta muitos subsistemas. O autor afirma serem três os princípios básicos que guiam os projetos da natureza: otimização, ciclo fechado e interdependência. Não há desperdício na natureza, sempre são encontradas formas que aperfeiçoem os materiais e a energia. Da mesma forma, tudo acontece em ciclos das marés, do sol, da lua, as estações. Ademais, cada acontecimento gera suas consequências, que darão fomento a outros acontecimentos.

O processo criativo de um projetista não conta somente com a inspiração, mas também com métodos e ferramentas que permitam a manifestação da criatividade. Esta pode surgir de inúmeros ambientes, inclusive, da própria natureza (DETANICO; TEIXEIRA; SILVA, 2010).

Janine Benyus foi uma das primeiras estudiosas a respeito do tema, lançando o livro Biomimicry - Innovation Inspired by nature que define os conceitos básicos dessa abordagem. São eles:

a) Natureza como modelo: Estudar os modelos da natureza e imitá-los ou usá-los como inspiração, com o intuito de resolver os problemas humanos; 
b) Natureza como uma medida: Usar o padrão ecológico para julgar a relevância e a validade das nossas inovações. Após bilhões de anos de evolução, a natureza aprendeu o que funciona, o que é mais apropriado e o que perdura;

c) Natureza como um mentor: Nova forma de observar e avaliar a natureza. Preocupar-se não no que podemos extrair do mundo natural, mas no que podemos aprender com ele (BEYNUS,1997).

O método de projetos com abordagem da Biomimética consiste em três etapas fundamentais: Como captar um princípio natural, como encontrar um conceito de projeto para a estrutura e como desenvolver o conceito. O Biomimicry Institute é um grupo de pesquisa que visa divulgar metodologias que permitam a realização de projetos com biomimética (BEYNUS, 1997). Seu portal, o ASKNATURE, avalia diversos aspectos funcionais da natureza, além de cases utilizados no design de produto, além metodologia que une as etapas da Biomimética com o pensamento convergente e divergente do processo, focando a cada etapa do processo em soluções que ampliam as discussões para a posterior convergência de ideias, como apresentado na Figura 04.

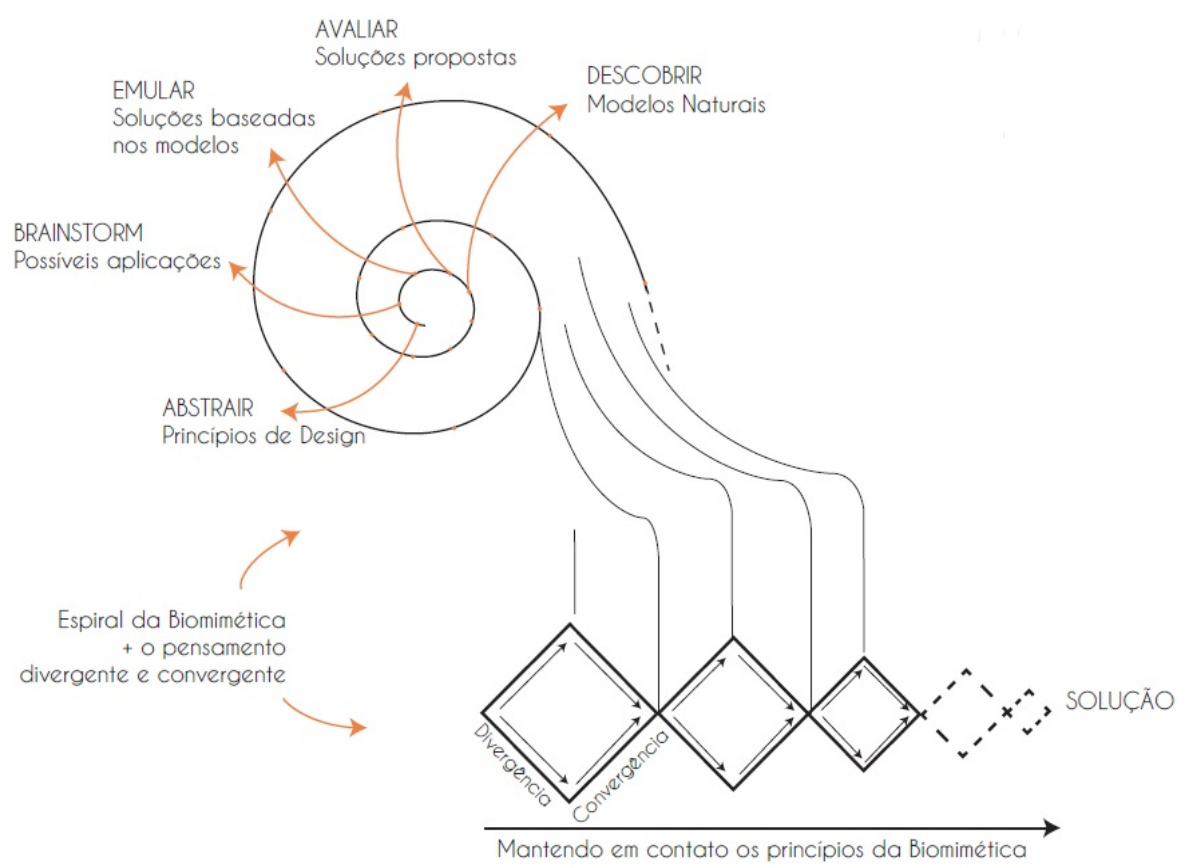

Figura 4 - Associação de metodologias. Elaborado pelos autores a partir de dados do http://www.asknature.com

A partir do referencial encontrado no ASK NATURE, buscou-se a compreensão dos métodos de voo de diferentes tipos de sementes aladas, como forma de criar bases para a compreensão e aplicação no desenvolvimento do projeto. A seguir, são apresentadas algumas espécies e suas estratégias.

A semente de Acer pseudoplatanus pode girar em voo, como apresentado na Figura 5. O comportamento de sementes e frutos com tais características é semelhante ao de um helicóptero, e resulta da combinação do ângulo de ataque e derrapagem gerada pela lâmina ligeiramente curvada. As velocidades locais desenvolvidas na ponta da asa são relativamente altas e, em conjunto com os 
momentos correspondentes, produzem uma grande estabilidade dinâmica (ASK NATURE, 2010).
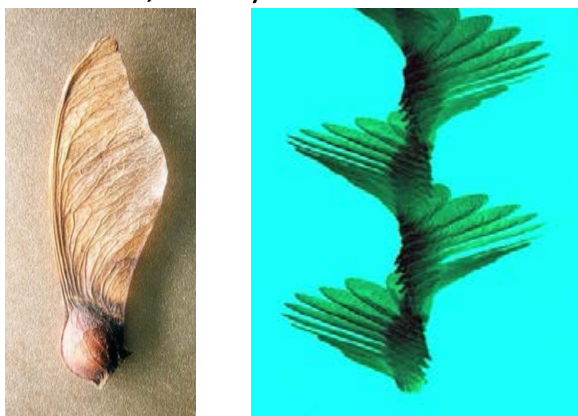

Figura 5- Sementes de Acer pseudoplatanus e seu plano de voo.

Fonte: http://www.asknature.com

A planta Alsomitra vine é uma trepadeira que cresce nas árvores das florestas tropicais em direção à copa e luz solar. Em grandes alturas, cresce vagens que contêm centenas de sementes aladas. Ao contrário da de Acer pseudoplatanus, sua semente possui um voo estável, deslizando com suas asas de estrutura fina. A semente tem cerca de 1 milímetro de espessura, sendo posicionada ao centro da estrutura,gerando seu equilíbrio ao plainar(ASK NATURE, 2010).

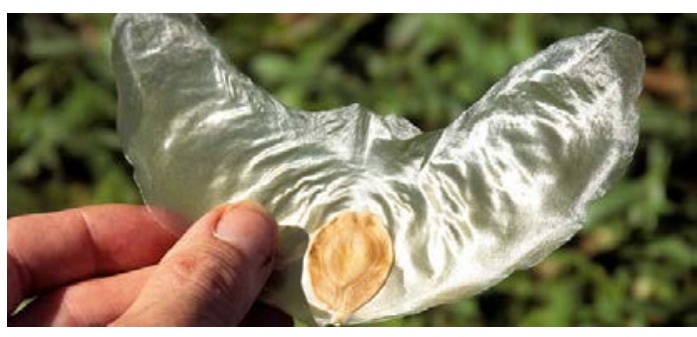

Figura 6- Semente de Alsomitra Vine.

Fonte: http://www.asknature.com

\subsection{Produto proposto}

Sistemas mais simples e eficazes devem ser desenvolvidos, tanto com relação ao material utilizado e a sua prospecção de produção em larga escala, quanto à proteção das sementes e sua dispersão por via aérea.

Avaliou-se como base de experimentos o uso de sementes de Guapuruvu, planta nativa da família Fabaceae, que produz árvores de 15 a 20 metros de altura, podendo alcançar 30 metros, de acordo com as condições onde estiver plantada. A copa estrutura-se em formato de guarda chuva, e apresenta tronco longo. As folhas são compostas e os galhos chegam a mais de um metro de comprimento. A flor, de cor amarela em tom intenso, se destaca na vegetação. As sementes são liberadas pelo fruto no fim do outono e no início do inverno (HERBÁRIO FLORESTAL, 2011).

A escolha da semente foi realizada após a consulta à equipe de botânica do Museu de História Natural e Jardim Botânico da Universidade Federal de Minas Gerais (Horto - UFMG), que afirmaram ser esta espécie um representante da categoria secundária inicial de sucessão ecológica, e já é utilizada em processos de reflorestamento. Além disso, possui uma boa resistência às intempéries externas do ambiente. 
Para a materialização da ideia, foram realizados modelos tridimensionais funcionais como forma de validar os aspectos do sistema. Após as gerações de alternativas iniciais, foram realizados modelos feitos de papel vegetal e sementes de milho. Essas amostras permitiram compreender o peso o tamanho necessário para que o módulo pudesse ser lançado e plainasse pelo ar, bem como a melhor posição necessária para equilibrar o sistema. Pelos ensaios elaborados, evidenciou-se que quanto maior o peso, maior deveria ser a área de contato do planador.

Em seguida, foram realizados modelos a partir de material alternativo, papel parana em espessura de $1 \mathrm{~mm}$. Nesta etapa, foram avaliadas a superfície de contato total e possíveis regiões para a disposição das sementes. Em uma etapa sucessiva, foram realizados modelos funcionais feitos de papel 90 gramas, com as sementes nativas das plantas selecionadas. Adiante, os modelos foram confeccionados com o uso de filmes de PVC $0,5 \mathrm{~mm}$, das sementes definidas do projeto e fita adesiva. A importância dessa fase deu-se principalmente pela definição da área total utilizada, e foram definidos os modos de encaixe e fixação para a semente.

Realizou-se, assim, um modelo em prototipagem rápida em $A B S$, para a análise da estrutura e posteriormente, a realização do modelo final, em processo de termoformagem. O modelo em ABS, assim, serviu de molde positivo para a realização dos outros modelos, realizados com filme de PVC. O processo foi realizado na oficina da Escola de Design. A Figura 07 apresenta o esquema e fases de desenvolvimento do projeto.

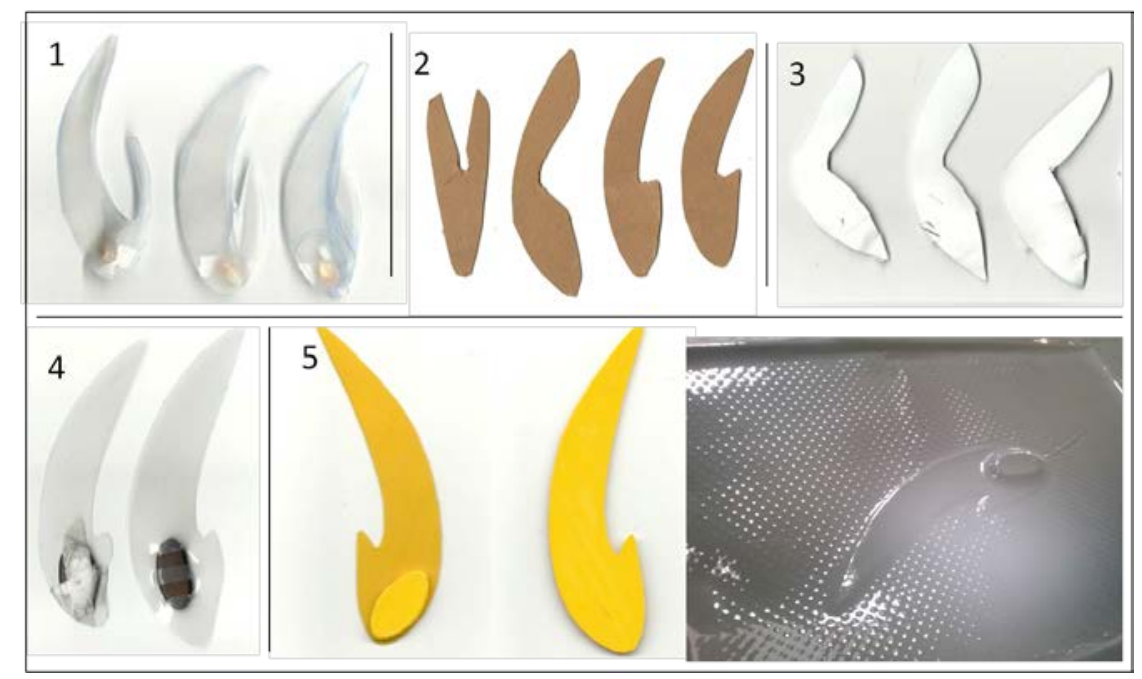

Figura 7- Processo de produção de modelos e protótipo final. 1: testes com papel vegetal e milho/ 2: testes com papel parana/ 3: testes com papel 90gr/ 4: testes com filme PVC/ 5:modelo em prototipagem rápida e termoformagem em filme PVC. Elaborado pelos autores.

\section{CONCLUSÃO}

Conforme apresentado ao longo do artigo, o projeto teve como finalidade utilizar o design como ferramenta capaz de compreender, analisar e propor soluções que visem à melhoria do procedimento de reflorestamento realizado por vias aéreas, além de permitir discussões a respeito do tema. 
É evidente que um projeto de tamanha complexidade deve ser realizado sob a ótica de uma equipe multidisciplinar, envolvendo participantes das mais variadas áreas de conhecimento, pois só assim podem-se fomentar práticas que sejam realmente eficazes diante do atual cenário de degradação enfrentado. No futuro, o projeto pode ser compartilhado e estudado para uma efetiva execução, podendo ser inclusive ampliado o campo de estudo para a aplicação de polímeros biodegradáveis adicionados de fertilizantes, avaliando sua germinação em espécies nativas. Ademais, a estruturação do problema a partir da abordagem do design é capaz de criar soluções mais eficazes as já utilizadas, e como visto ao longo dessa análise, existem diversos projetos conceituais sobre reflorestamento, mas faltam os que aliem à realidade e as necessidades encontradas no setor.

\section{AGRADECIMENTOS}

À Brigada Aérea do Corpo de Bombeiros de Minas Gerais, à Brigada Aérea da Polícia Civil de Minas Gerais, à Escola de Aviação Civil (FAE), à Coordenação de Proteção e Recursos Naturais da Fibria Celulose, e à equipe de botânica do Museu de História Natural e Jardim Botânico da Universidade Federal de Minas Gerais.

\section{REFERÊNCIAS}

ASK NATURE, 2010 Disponível em

<http://www.asknature.org/strategy/b4d8f858db37c80adfbd6543b4ef526>. Acesso em Mai 2016.

BELLOTTO, Andrezza; GANDOLFI, Sergius; RODRIGUES, Ricardo. Restauração fundamentada no plantio de árvores, sem critérios ecológicos para a escolha e combinação das espécies. In Pacto pela restauração da Mata Atlântica: Referencial dos conceitos e ações de restauração florestal. São Paulo: LERF/ ESALQ: Instituto Bioatlântica, 2009.

BEYNUS, Janine. Biomimicry: Innovation Inspired by Nature. Editora William Morrow \& Co., Califórnia, 1997.

BOURSCHEIT, Aldem. Código Florestal completa um ano com poucos avanços. Disponível em<http://www.wwf.org.br/informacoes/noticias_meio_ambiente_e_natureza/?3498 2/Cdigo-Florestal-completa-um-ano-com-poucos-avanos\#> acesso em Jun 2016.

BRANCALION, Pedro; ISERNHANGEN, Ingo; GANDOLFI, Sergius; RODRIGUES, Ricardo Abandono da cópia de modelo de floresta madura e foco na restauração dos processos ecológicos responsáveis pela reconstrução de uma floresta. In Pacto pela restauração da Mata Atlântica: Referencial dos conceitos e ações de restauração florestal. São Paulo: LERF/ ESALQ: Instituto Bioatlântica, 2009.

DETANICO, Flora; TEIXEIRA, Fábio; SILVA; Tânia. A biomimética como método criativo para o projeto de produto. 2010 Pg Design, Design e Tecnologia, UFRGS. Disponível em<http://www.pgdesign.ufrgs.br/designetecnologia/index.php/det/article/viewFile/ 52/33 >Acesso em Jan 2016.

GUIMARÃES, Mariane. Na natureza tudo se cria (página 11 a 15). ABC DESIGN. Edição trimestral Julho/Agosto/Setembro de 2011. 
HERBÁRIO FLORESTAL Guapuruvu, 2011. Universidade Federal de Santa Maria, Departamento de Ciências Florestais. Disponível em

<http://coralx.ufsm.br/herbarioflorestal/especie_detalhes.php?nome_filtrado=guapur uvu >Acesso em Jan 2016.

INSTITUTO BRASILEIRO DO MEIO AMBIENTE E RECURSOS NATURAIS RENOVÁVEIS (IBAMA). Manual de recuperação de áreas degradadas pela mineração: técnicas de revegetação, 1990.

INSTITUTO DE PESQUISAS TECNOLÓGICAS (IPT). Reflorestamento por semeadura aérea na Serra do Mar, 1989. Disponível em

<http://www.ipt.br/centros_tecnologicos/CTGeo/cases/4reflorestamento_por_semea dura_aerea_na_serra_do_mar.htm>Acesso Fev 2016.

JUNIOR, Valnei. O helicóptero na aviação agrícola brasileira. Universidade Tuiuti do Paraná, 2011. Disponível em <http://tcconline.utp.br/wp-

89content/uploads/2013/06/O-HELICOPTERO-NA-AVIACAO-AGRICOLA.pdf> Acesso 15 Jan 2016.

KAZAZIAN, Thierry. Haverá a idade das coisas leves. São Paulo, Editora Senac São Paulo, 2005.

PAGNOCELLI, Bruno. Projeto Nucleário, 2009. Disponível em

<http://vimeo.com/40417949> Acesso Jan 2016.

REIS, Dalcacio. Product Design in the sustainable era. Editora Taschen GmbH,Hohenzollernring Alemanha, 2010.

RODRIGUES, Ricardo; BRANCALION, Pedro; ISERNHAGEN, Ingo. Pacto pela restauração da mata atlântica: referencial dos conceitos e ações de restauração florestal. São Paulo: LERF/ESALQ : Instituto BioAtlântica, 2009.

SILVEIRA, Vinícius. Cenário atual da aviação agrícola no Brasil. São José dos Campos, São Paulo, 2004. Disponível em<http://www.agrotec.etc.br/downloads/dissertacao_ViniciusSilveira.pdf $>$ acesso em Jan 2016. 